\title{
Mothers' Experience in Parenting Disabled Children (Case study: speech-language delay children)
}

\author{
Haerani Nur \\ Universitas Airlangga \\ Surabaya, Indonesia
}

\begin{abstract}
Parenting for children with special needs is not an easy thing for the mothers, including for the mothers who have children with developmental delay in speech and language. This phenomenological qualitative study aims to explore mother's experiences in parenting with speech-and-language delay children. Interviews were conducted with five mothers. The study found that experiencing some problems that cause negative emotional reactions and led to bad parenting behaviour. Hope is a major factor that can change the mother's perspective about their children. It can result in positive parenting behaviours for children's development. These results indicate that hope plays significant roles in the context of parenting children with delayed development.
\end{abstract}

\section{Keywords_- parenting; special children}

\section{INTRODUCTION}

Childhood education is always an interesting topic to discuss especially in Indonesia. In many cases, Childhood education is changing over the time because of the dynamic issues related to this topic. However, the main interest concerns are how the community or parents are focusing their parenting methods or parenting education to their children.

The phenomenon of speech and language delay in children in Indonesia showed an increasing trend [1], [2]. Furthermore, speech and language skills are a developmental task that must be mastered to articulate wants and needs. Delays in speech and language acquisition are an early indicator of developmental deficits that can affect academic performance for children in school, provide critical tools for learning, engaging in social relationships, behaviour and emotion regulation from infancy onward [3], [4].

Parents have a very important role for children who have developmental delays. Parents are the detection of the most accurate in identifying barriers to the growth experienced by the child [5]. Besides that, parenting style is one of the significant factors for children's development, in particular for children with or at risk of developmental delay [6]
However, parents sometimes difficult to carry out their role optimally. Parents of children with disabilities or developmental delays may experience caregiver strain due to parenting stress, disrupted family relationships, financial difficulties, restrictions on leisure activities, and disrupted social relationships. [7].

Several studies have found that mothers with children who have developmental disabilities will experience more severe psychological impact, such as high stress [8], [9], depression [10], [11] , often experience grief, shock, loss of control, and hopelessness upon their child's initial diagnosis [12].

The goals of the present study were to obtain a description of parenting mothers of children with delayed speech and language development. The results of this study are expected to be the basis to perform some interventions in addressing the issue of parenting for children with delays in speech and language development.

\section{RESEARCH METHOD}

\section{A. Setting and Design}

This research was conducted at several schools and therapy centres in the city of Makassar, South Sulawesi, Indonesia. The city has been chosen because it has a relatively high level of speech and language delay in children. It was designed as a phenomenological qualitative study. It is interested in describing and constituting the meaning of the human lifeworld in many variances [13].

\section{B. Participants and Data Collections}

The study involved five participants were selected based on the following criteria: mothers with children who experienced delays in speech and language, can share their parenting experiences, and willing to be a participant by completing the informed concern. Mothers were interviewed to find description about their parenting experience. 


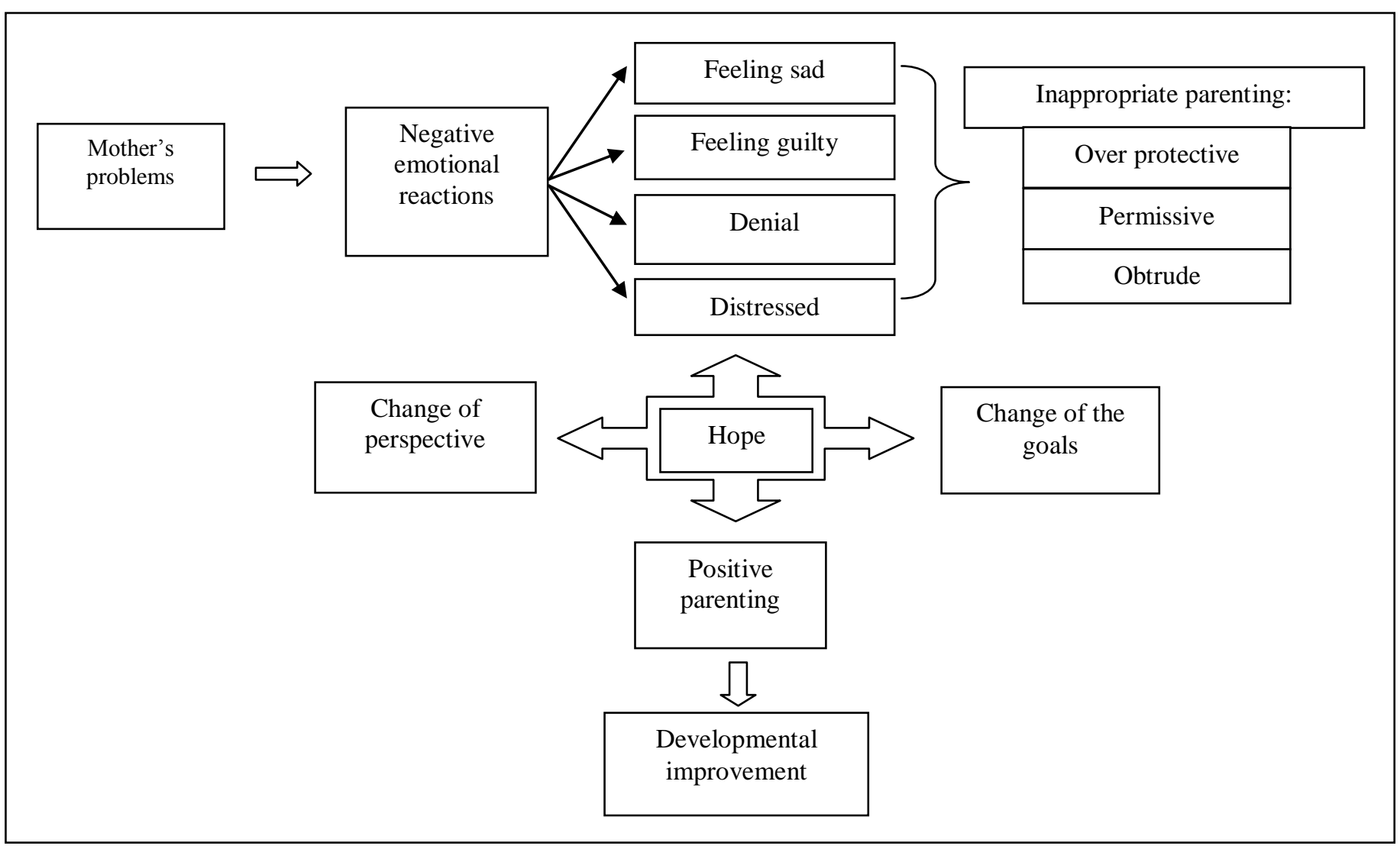

Fig. 1. Ilustration of research finding

\section{Data Analysis}

All interviews were recorded, transcribed verbatim, and analyzed. A phenomenological analysis was used, according to [13].

\section{RESULT AND DISCUSSION}

Education and Learning Process in Early Childhood Education Should be done with the aim of providing meaningful concepts for children through real experience. It is only the experience that enables the child to demonstrate activity and curiosity optimally. On the other hand, the position of an educator is a mentor or facilitator for the children. Through the educational process is expected to avoid the formation of the learning process that is only oriented at the will of teachers who put children passively and teachers become dominant.

The study found that mothers with children who have developmental delays in speech and language, experiencing some problems that cause negative emotional reactions and lead to bad parenting behaviour. In this study found that the mother tends overprotective, permissive, and obtrude.

Emotions or person's feelings due to events or responses arising from the stimuli that trigger emotions. Regarding parenting disabilities children, the responses that appear to the mother are negative. Negative response that is displayed is feeling sad, feeling guilty, denial and distressed. When a mother sees her child experiencing speech delay, then the emotion that comes up is a sense of sadness. The trigger of such sadness is the difference in the ability of a disabled child compared with a completely grown child. Emotion is evolved due to the mother's desire to build the social ability of children. The child is unable to communicate with his peers.

Mothers of disabilities children sometimes feel depressed and personality closed. These emotional reactions are triggered by social stressors. A mother even sometimes feels the cause of invalidity occurs in her child. In addition to the negative emotional reaction, the mother also behaves inappropriately on parenting. The child's disability causes a mother to behave negatively on parenting, such as overprotective and permissive. The attitude is characterized by overly indulgent behaviour and is less liable to make clear rules for children.

The expectation of a parent who has children with speech delay hope of being able to give a positive parenting. Parenting patterns that develop the child's creativity and emotionality are needed in his growth. By him, parents should be able to change perceptions about the growth of disabled children.

Inappropriate parenting causes disruption to the child's emotional growth. This is a time when the children begin to be sensitive/sensitive to receive an artificial pool. The sensitivity period in each child is different, along with the growth rate and individual development of the child. The sensitivity period is the maturity of physical and psychic functions that are ready to respond to the stimulation provided by the environment. This 
period is also a time of the foundation for developing cognitive, motor, linguistic, socio-emotional, religious and moral skill.

Figure 1 illustrates the results of the study which illustrates that the hope becomes important factors. It can facilitate the mother in applying appropriate parenting for the child. This study found that when the mother can change her hopes, adjusting hopes with the child's condition, the mother will adjust their parenting behaviour with the child's needs.

The previous study has established that hope is the life instinct [14], life force [15] for the people. Hope is something that helps the people to jump over difficult things [16]. Hope is a positive transformation and dynamic process that helped parents to reframe their lives given their experience with children with disabilities [17].

\section{CONCLUSION}

Mothers with children who have developmental delays in speech and language, experiencing some problems which led to a negative emotional reaction, and affect their parenting behaviour. Hope is identified as an important factor. It can facilitate the mother in applying appropriate parenting behaviour.

\section{REFERENCES}

[1] D. P. Cantwell, L. Baker, and R. E. Mattison, "The Prevalence of Psychiatric Disorder in Children with Speech and Language Disorder An Epidemiologic Study," J. Am. Acad. Child Psychiatry, vol. 18, no. 3, pp. 450-461, 1979.

[2] E. Frankenberg, V. Beard, and M. Saputra, "The Kindred Spirit: the ties that bind Indonesian children and their parents," Asian J. Soc. Sci., vol. 27, no. 2, pp. 65-85, 1999.

[3] A. P. Kaiser and M. Y. Roberts, "Advances in early communication and language intervention," J. Early Interv., vol. 33, no. 4, pp. 298-309, 2011.

[4] N. J. Cohen, "The impact of language development on the psychosocial and emotional development of young children," Encycl. Early Child. Dev., vol. 2002, pp. 1-7, 2005.

[5] F. P. Glascoe and K. P. Marks, "Detecting children with developmental, behavioral problems: The value of collaborating with parents," Psychol. Test Assess. Model., vol. 53, no. 2, pp. 258-279, 2011.

[6] S. Nam and J. Chun, "Influencing factors on mothers' parenting style of young children at risk for developmental delay in South Korea: The mediating effects of parenting stress," Child. Youth Serv. Rev., vol. 36, pp. 81-89, 2014.

[7] Y.-H. Yang, "Parents and young children with disabilities: The effects of home-based parent education in music on parent-child interactions." THE FLORIDA STATE UNIVERSITY, 2013.

[8] V. Lopez, T. Clifford, P. Minnes, and H. Ouellette-Kuntz, "Parental stress and coping in families of children with and without developmental delays," J. Dev. Disabil., vol. 14, no. 2, pp. 99-104, 2008.

[9] R. C. Tervo, "Developmental and behavior problems predict parenting stress in young children with global delay," J. Child Neurol., vol. 27, no. 3, pp. 291-296, 2012.

[10] M. Rudolph, F. Rosanowski, U. Eysholdt, and P. Kummer, "Anxiety and depression in mothers of speech impaired children," Int. J. Pediatr. Otorhinolaryngol., vol. 67, no. 12, pp. 1337-1341, 2003.

[11] M. B. Olsson and C. P. Hwang, "Depression in mothers and fathers of children with intellectual disability," J. Intellect. Disabil. Res., vol. 45, no. 6 , pp. 535-543, 2001.

[12] C. Johnston et al., "Factors associated with parenting stress in mothers of children with fragile X syndrome," J. Dev. Behav. Pediatr., vol. 24 , no. 4, pp. 267-275, 2003.
[13] C. Moustakas, Phenomenological research methods. Sage, 1994.

[14] K. Menninger, "The academic lecture: Hope," Am. J. Psychiatry, vol. 116, no. 6, pp. 481-491, 1959.

[15] K. Dufault and B. C. Martocchio, "Symposium on compassionate care and the dying experience. Hope: its spheres and dimensions.," Nurs. Clin. North Am., vol. 20, no. 2, pp. 379-391, 1985.

[16] J. Kylmä, K. Vehviläinen-Julkunen, and J. Lähdevirta, "Dynamics of hope in HIV/AIDS affected people: an exploration of significant others' experiences," Res. Theory Nurs. Pract., vol. 17, no. 3, pp. 191-205, 2003.

[17] S. Kausar, R. F. Jevne, and D. Sobsey, "Hope in families of children with developmental disabilities," J. Dev. Disabil., vol. 10, no. 1, pp. 3546, 2003. 